\title{
Application of orange essential oil as an antistaphylococcal agent in a dressing model
}

\author{
Arunachalam Muthaiyan ${ }^{1}$, Debabrata Biswas ${ }^{1,2}$, Philip G Crandall ${ }^{1}$, Brian J Wilkinson ${ }^{3}$ and Steven C Ricke ${ }^{1 *}$
}

\begin{abstract}
Background: Staphylococcus aureus is the pathogen most often and prevalently involved in skin and soft tissue infections. In recent decades outbreaks of methicillin-resistant $S$. aureus (MRSA) have created major problems for skin therapy, and burn and wound care units. Topical antimicrobials are most important component of wound infection therapy. Alternative therapies are being sought for treatment of MRSA and one area of interest is the use of essential oils. With the increasing interest in the use and application of natural products, we screened the potential application of terpeneless cold pressed Valencia orange oil (CPV) for topical therapy against MRSA using an in vitro dressing model and skin keratinocyte cell culture model.

Methods: The inhibitory effect of CPV was determined by disc diffusion vapor assay for MRSA and vancomycin intermediate-resistant S. aureus (VISA) strains. Antistaphylococcal effect of CPV in an in vitro dressing model was tested on S. aureus inoculated tryptic soya agar plate. Bactericidal effect of CPV on MRSA and VISA infected keratinocyte cells was examined by enumeration of extra- and intra-cellular bacterial cells at different treatment time points. Cytotoxic effects on human skin cells was tested by adding CPV to the keratinocyte (HEKO01) cells grown in serum free KSFM media, and observed by phase-contrast microscope.
\end{abstract}

Results: CPV vapour effectively inhibited the MRSA and VISA strains in both disc diffusion vapour assay and in vitro dressing model. Compared to untreated control addition of 0.1\% CPV to MRSA infected keratinocyte decreased the viable MRSA cells by $2 \log$ CFU/mL in $1 \mathrm{~h}$ and in VISA strain $3 \log$ CFU/mL reduction was observed in $1 \mathrm{~h}$. After $3 \mathrm{~h}$ viable $\mathrm{S}$. aureus cells were not detected in the $0.2 \%$ CPV treatment. Bactericidal concentration of CPV did not show any cytotoxic effect on the human skin keratinocyte cells in vitro.

Conclusions: At lower concentration addition of CPV to keratinocytes infected with MRSA and VISA rapidly killed the bacterial cells without causing any toxic effect to the keratinocytes. Therefore, the results of this study warrant further in vivo study to evaluate the potential of CPV as a topical antistaphylococcal agent.

Keywords: MRSA, VISA, S. aureus, Antibiotic resistance, Natural antimicrobials, Orange essential oil

\section{Background}

The highly adaptive $S$. aureus is the causative agent of a wide variety of human infections, ranging from superficial skin infections to deep abscesses and more serious life threatening infections [1]. Since the 1990s, methicillinresistant $S$. aureus (MRSA) has accounted for an increasing proportion of community associated infections in the U.S. [1,2]. MRSA has become a primary cause of skin and soft tissue infections among persons without extensive exposure to healthcare settings. Data obtained from nationally

\footnotetext{
* Correspondence: sricke@uark.edu

${ }^{1}$ Center for Food Safety and Department of Food Science, University of Arkansas, Fayetteville, AR 72701, USA

Full list of author information is available at the end of the article
}

representative ambulatory care surveys in the U.S. show that the infections associated with skin and soft-tissue increased from 8.6 million in 1997 to 14.2 million in 2005 [3]. Skin and soft tissue infections (SSTIs) involve microbial invasions of the primary host defence barriers epidermis and underlying soft tissues [4,5]. Likewise, patients hospitalized with burn wounds are at increased risk of developing microbial colonization and infection caused by S. aureus. Previous studies revealed that $S$. aureus is the most frequently isolated bacterial species among the other pathogens from the burn wounds [6,7].

Generally dressings and topical antimicrobial agents are routinely used to prevent skin and burn infections

\section{Biomed Central}


and also to keep the wound moist to promote healing [6]. Although, a small number of antibiotics are used as prophylactics to prevent wound infection they are not routinely administered to burn patients due to the high cost and the risk of adverse side effects [8]. Since, the constant use of antibiotics select the bacterial populations including $S$. aureus that are resistant to multiple antibiotics alternative therapies and new medical practices are very much needed [9-11]. One such approach is the search of biologically active pharmacophores from natural resources and traditional medicines [12-16]. Natural products have been investigated and utilized to alleviate disease since early human history. Before the "synthetic era", $80 \%$ of all medicines were obtained from roots, barks, leaves, flowers, seeds and fruits [17].

Numerous studies have explored the promising novel antimicrobial candidates from plant derived essential oils (EOs). These EOs are particularly interesting since some oils have been used by native groups for curative purposes in the past $[18,19]$. Many plants EOs have demonstrated for antimicrobial activity against variety of bacterial pathogens $[20,21]$. One such a prominent example is tea tree oil obtained from the Australian tree Melaleuca alternifolia. Tea tree oil has been shown to be active against a wide range of microorganisms including $S$. aureus [20,22]. In previous studies the antimicrobial activities of EOs have also been investigated and their actions against various pathogens, including clinical MRSA isolates, have been demonstrated [23-30].

Fisher et al. reported the effectiveness of citrus EOs and vapours of lemon and the citrus EO components citral, limonene, and linalool against a number of common foodborne pathogens Listeria monocytenes, S. aureus, Bacillus cereus, E. coli O157, and Campylobacter jejuni both in vitro and on food models [31]. In our laboratory we have demonstrated the inhibition of Salmonella [32], Listeria [33,34], Escherichia coli O157: H7 [35], Campylobacter [36], and methicillin resistant S. aureus [37] by citrus derived cold pressed Valencia orange oil, terpeneless Valencia orange oil, cold pressed orange terpenes, high purity orange terpenes, d-limonene, and terpenes from orange essence. In our previous study the inhibitory and cell wall lytic effect of $0.1 \%$ and $0.2 \%$ cold pressed terpeneless Valencia orange oil (CPV) against MRSA and VISA was demonstrated by disc diffusion and agar dilution methods and confirmed by genomic transcriptional profiling and electron microscopy [37]. With the increasing interest in the use and application of natural antimicrobial agents for the therapy in the present study we evaluated the potential of CPV for topical therapy against MRSA by determining the antistaphylococcal effect of CPV in dressing model and $S$. aureus infected keratinocyte cell culture study.

\section{Methods}

\section{Bacterial strains}

Methicillin-susceptible S. aureus strain SH1000 [38], methicillin-resistant strains COL [39], $13136 \mathrm{p} \mathrm{m}^{-}$[40], and N315 [41], and vancomycin intermediate-resistant strains $13136 \mathrm{p} \mathrm{m}^{-} \mathrm{V}_{20}$ [42], and Mu50 [41] were used in this study. Depending on the experimental condition described in the following sections bacterial strains were grown in either tryptic soya broth (TSB) or tryptic soya agar (TSA) media (Difco Laboratories, Inc. Detroit, MI) and incubated at $37^{\circ} \mathrm{C}$ for $18 \mathrm{~h}$.

\section{Orange essential oil}

Commercially available terpeneless cold pressed Valencia orange oil was obtained from Firmenich Citrus Center, Safety Harbor, FL, USA. CPV is derived from mechanical extraction of the orange oil which is further concentrated under vacuum [43]. The major components of CPV are Linalool 20.2\%, Decanal 18\%, Geranial 9.1\%, $\alpha$-Terpineol 5.8\%, Valencene 5.2\%, Neral 5\%, Dodecanal 4.1\%, Citronellal 3.9\%, and Limonene 0.3\% [36]. The most predominant compounds are the alcohol linalool (20.2\%) followed by decanal (18\%), and geranial (9.1\%), the amount of limonene is much lower at $0.3 \%$ [36].

\section{Disc diffusion vapor assay for screening the inhibitory effect of CPV}

Disc diffusion vapor assay was carried out by the method described by Goñi et al. [44] and Edwards-Jones et al. [45]. Overnight cultures of the S. aureus (7 log CFU/mL) were streaked on sterile TSA (Difco Laboratories, Inc.) using a cotton swab dipped into the culture. The swab was used to streak the agar plate to produce a lawn of growth by streaking the plate in 3 different directions. Ten $\mu \mathrm{L}$ of $100 \%$ CPV was aseptically pipetted onto sterile 6-mm paper discs (Becton Dickson, Franklin Lakes, NJ) and subsequently the CPV impregnated paper discs were aseptically placed in the centre of the lid of the Petri dish. Control plates were prepared by adding $10 \mu \mathrm{L}$ of sterile water to the filter discs. The Petri dishes were subsequently sealed using parafilm and incubated at $37^{\circ} \mathrm{C}$ in an inverted position. The diameters of zones of inhibitions were measured in $\mathrm{mm}$ after $24 \mathrm{~h}$ of incubation. The assays were carried out on three different occasions in duplicate.

\section{In vitro dressing model study}

In vitro dressing model was designed by a modification of the method described by Edwards-Jones et al. [45]. Briefly, $10 \mu \mathrm{L}$ aliquot of CPV (100\%) was spotted in four different areas on the sterile 10.2 x $10.2 \mathrm{~cm}, 12$ ply cotton gauze dressing pad (Duka Corp. Happauge, NY) (Figure 1a). For control plates $10 \mu \mathrm{L}$ of sterile deionized water was spotted in the gauze dressing pad. TSA plates were seeded with a suspension of $7 \log \mathrm{CFU} / \mathrm{mL}$ of 

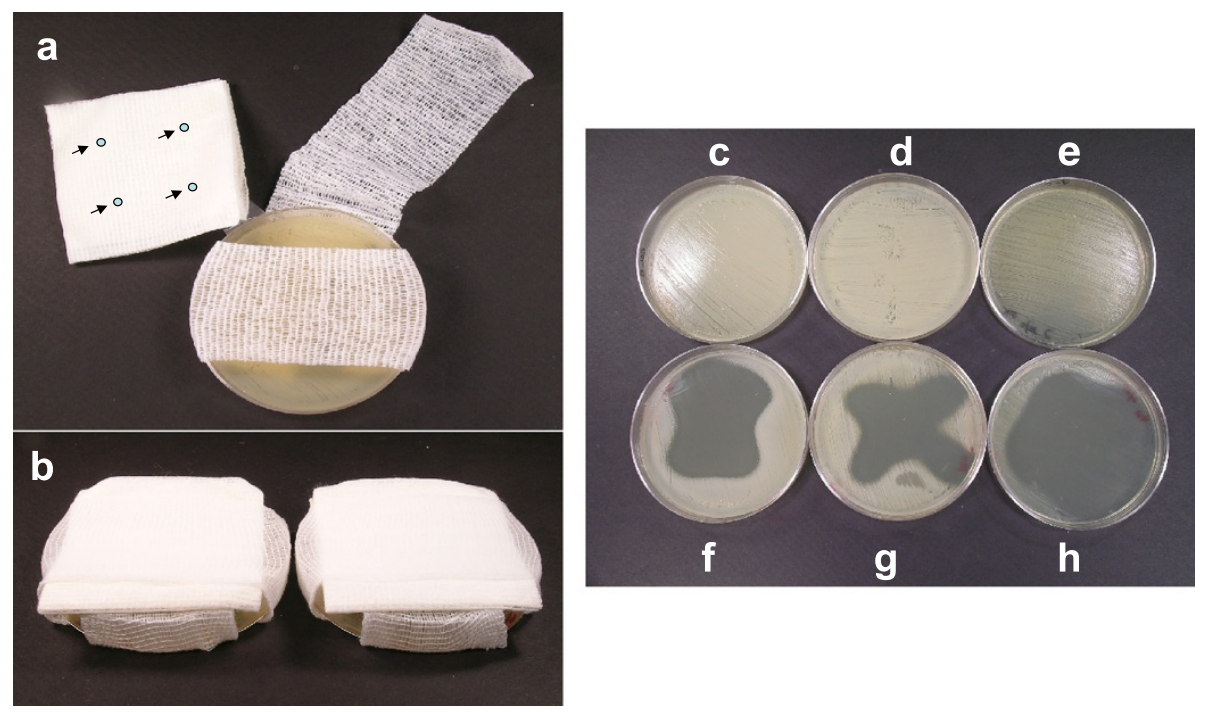

Figure 1 Dressing model using an agar plate. (a), arrows indicate the CPV spots on gauze dressing pad; (b), complete setup of dressing model with gauze dressing pad wrapped with bandage. Untreated control plates of S. aureus strains (c), COL; (d), Mu50; and (e), 13136 p ${ }^{+}{ }^{+} V_{20}$. Inhibition of S. aureus (f), COL; (g), Mu50; and (h), $13136 \mathrm{p}^{-} \mathrm{m}^{+} \mathrm{V}_{20}$ caused by CPV.

MRSA strains COL, Mu50 or VISA strain $13136 \mathrm{p}^{-} \mathrm{m}^{+} \mathrm{V}_{20}$ and covered with single layer of sterile bandage (QMD Medical, Quebéc, Canada) without touching the inoculated agar surface. As shown in Figure 1a CPV spotted gauze dressing pad was placed on the bandage by CPV spots facing towards the inoculated agar surface and wrapped with bandage to hold the gauze dressing pad on the Petri plate (Figure 1b). The dressing model Petri plates were subsequently incubated at $37^{\circ} \mathrm{C}$ for $24 \mathrm{~h}$ and the treated plates were compared with untreated control to identify the visible inhibition zones. This study was carried out on three different occasions in duplicate.

\section{Keratinocyte cell culture}

Homo sapiens skin keratinocyte (HEK001) ATCC CRL$2404^{\text {TM }}$ cells were grown in keratinocyte serum free media (K-SFM) with two additives, bovine pituitary extracts (BPE) and human recombinant epidermal growth factor (EGF) (Invitrogen, Carlsbad, CA). Cells were grown routinely in a $75 \mathrm{~cm}^{2}$ flask at $37^{\circ} \mathrm{C}$ in a $5 \% \mathrm{CO}_{2}$-humidified incubator. Ninety percent confluent cultures were trypsinized, and new cultures were prepared by seeding with $10^{5}$ cells $/ \mathrm{ml}$ in $75 \mathrm{~cm}^{2}$ flasks. For cytotoxicity and infection assays, BD Falcon ${ }^{\mathrm{TM}}$ 24-well tissue culture plates (BD, Franklin Lakes, NJ) were seeded with $10^{5}$ cells $/ \mathrm{ml} /$ well and incubated at $37^{\circ} \mathrm{C}$ in a humidified $5 \% \mathrm{CO}_{2}$ incubator for 18 to $20 \mathrm{~h}$ to obtain a semi-confluent monolayer. Prior to assays, the monolayers were washed and incubated with K-SFM medium without antibiotic.

\section{Cytotoxicity assay}

The MIC of CPV for the $6 \mathrm{~S}$. aureus strains used in this study was previously determined as $0.18 \%$ for the strains $13136 \mathrm{p} \mathrm{m}^{-}$and $13136 \mathrm{p}^{-} \mathrm{m}^{+} \mathrm{V}_{20}$ and $0.2 \%$ for strains COL, Mu50, and N315 [37]. Based on our previous results, 0.1\% and $0.2 \%$ of CPV was prepared using dimethyl sulfoxide (DMSO) as a dispersing agent and added to the HEK001 cell monolayers and incubated for $24 \mathrm{~h}$. After incubation, the cell monolayer was observed under phase-contrast microscope (Olympus, Japan). One set of HEK001 cell monolayer without any treatment and another set with equal volume of DMSO used in the CPV treatment were used as controls. To compare a typical cytotoxicity one set of HEK001 cell monolayer was treated with a known skin irritant SDS (25 $\mu \mathrm{g} / \mathrm{mL})$ [46].

\section{S. aureus infection assay}

Adherence and invasion assays were performed using a modified procedure derived from Harvey et al. [47]. Briefly, one loopful of overnight grown bacterial cells were collected from TSA plates and suspended in K-SFM media with additives. Aliquots $(100 \mu \mathrm{l})$ of the bacterial suspension, containing approximately $7 \mathrm{log} \mathrm{CFU} / \mathrm{mL}$ [multiplicity of infection (MOI) 1:100], were inoculated in duplicate in a 24-well tissue culture plate containing semiconfluent HEK001 cell monolayers. The CFUs of bacteria were determined simultaneously by serial dilution plate count on TSA plates. Infected monolayers were incubated for $2 \mathrm{~h}$ at $37^{\circ} \mathrm{C}$ under a $5 \% \mathrm{CO}_{2}$ humidified atmosphere to allow the bacterial cells to adhere and infect the HEK001 cells. Infected HEK001 monolayers were washed five times 
with K-SFM medium and re-incubated for $3 \mathrm{~h}$ in fresh media containing 0.1 or $0.2 \% \mathrm{CPV}$. For controls, infected HEK001 monolayers were re-incubated with fresh K-SFM medium alone or K-SFM medium with equal volume of DMSO used in CPV treatment. After 1, 2, and $3 \mathrm{~h}$ of incubation both controls and CPV treated HEK001 cells were lysed with $0.1 \%$ Triton X (Sigma, St. Louis, MO) in PBS for 15 min to detach the bacterial cells and subsequently the lysate containing bacterial cells were diluted and viable intra- and extra-cellular bacterial numbers were determined by counting the CFU on TSA plate. Results are expressed as the average number of bacterial CFU from three assays.

\section{Results and discussion}

\section{Effect of CPV vapour on S. aureus}

In an effort to explore the potential use of orange EO against antibiotic resistant $S$. aureus, in our earlier study inhibitory effects and mode of action of CPV against methicillin-susceptible strain SH1000, MRSA strains COL, $13136 \mathrm{p} \mathrm{m}^{-}$, and N315, and VISA strains $13136 \mathrm{p} \mathrm{m}^{-} \mathrm{V}_{20}$, and Mu50 were studied [37]. Compared to other tested EOs CPV effectively inhibited all the tested $S$. aureus strains [37]. Therefore, in the present study the effect of CPV vapour on $S$. aureus was examined on both agar plates and an in vitro dressing model to evaluate the potential of CPV for topical therapy. Generally to study the antimicrobial effect of vapour, EO impregnated paper disc is placed on the lid of Petri dish and subsequently the growth inhibition zone is measured and used to indicate the antimicrobial effect of EO [19,21].

In our disc diffusion CPV vapour study, growth of all the six $S$. aureus strains were inhibited at different levels (Table 1). The maximum diameter of inhibition zone $78.8 \pm 1.8 \mathrm{~mm}$ was observed in VISA strain $13136 \mathrm{p} \mathrm{m}^{-} \mathrm{V}_{20}$ followed by the MRSA strains $13136 \mathrm{p}^{-} \mathrm{m}^{+}$, COL, N315, and Mu50. The lower diameter of inhibition zone $17.8 \pm 1.4 \mathrm{~mm}$ was observed in an antibiotic susceptible strain SH1000. Similar to our observation, strain specific variation in the growth inhibition in $S$. aureus was

\begin{tabular}{|c|c|}
\hline S. aureus strain & Inhibition Zone $(\mathrm{mm})^{\mathrm{a}}$ \\
\hline SH1000 & $17.8 \pm 1.4$ \\
\hline COL & $64.0 \pm 2.2$ \\
\hline $13136 \mathrm{pm}^{-}$ & $70.2 \pm 1.4$ \\
\hline $13136 \mathrm{p}^{-} \mathrm{m}^{+} V_{20}$ & $78.8 \pm 1.8$ \\
\hline N315 & $62.6 \pm 2.5$ \\
\hline Mu50 & $21.0 \pm 2.6$ \\
\hline
\end{tabular}

${ }^{\mathrm{a}}$ Inhibition zones are average values of three independent trials \pm standard deviation of the mean (SD, $n=6)$. previously observed by Edwards-Jones et al. [45]. In their study, the most effective combination of geranium and

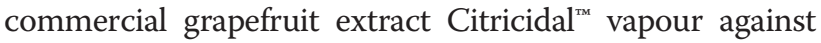
MRSA did not affect the growth of antibiotic susceptible S. aureus strain NCTC 6571 [45]. It has been previously noted that the degree of inhibition of bacterial growth by EOs considerably varies due to the complexity of EOs and characteristics of bacterial strains [48]. Related to results observed in our study Gaunt et al., [49] demonstrated the antistaphylococcal effect of evaporated volatile compounds from orange oil. In their study, agar plates inoculated with $S$. aureus strain 8532 were exposed in a large air-tight chamber to candle flames combined with the volatile bactericidal compounds $\beta$-pinene and orange oil and results showed that compared to plain candle addition of volatile oils significantly reduced the number of $S$. aureus colonies. Goñi et al. [44] also reported the susceptibility of various strains of Gram-negative and -positive microorganisms including $S$. aureus to vapour phase cinnamon, clove and a mixture of cinnamon and clove EOs. In their study they found that vapour phase of cinnamon, clove or mixture of cinnamon and clove EOs showed better inhibition of $S$. aureus growth than the direct contact disc diffusion method [44].

\section{Antistaphylococcal effect of CPV vapor in dressing model}

Our disc diffusion vapor assay proved that the vapor phase of the volatile components in the CPV serves as possible source of antimicrobial agents. Therefore, we considered assessment of the anti-staphylococcal effect of $\mathrm{CPV}$ vapor in an in vitro dressing model to evaluate the potential topical application of CPV. In this experiment the inhibitory effect of CPV was qualitatively evaluated by the presence or absence of inhibition zone by comparing the test and control dressing models (Figure 1c-h). As we observed in the disc diffusion vapor assay a similar inhibitory effect was observed in the dressing model as well. Growth of MRSA strains COL and Mu50 and VISA strain $13136 \mathrm{p} \mathrm{m}^{-} \mathrm{V}_{20}$ was inhibited by the vapor released from the CPV spotted gauze dressing pad and exhibited a clear inhibition zones on agar plates (Figure 1f-h). Our present study has demonstrated the potential of the CPV as an anti-MRSA agent in the vapor phase in both the disc diffusion assay and the in vitro dressing model. Effectiveness of the vapor phase EOs against microbial growth was shown to be better than the direct contact of EOs with the inoculated culture has already been reported in other studies [44,50]. In an in vitro dressing model study Edwards-Jones et al. [45] demonstrated the inhibitory effect of combination of geranium and commercial grapefruit extract Citricidal ${ }^{\mathrm{TM}}$ vapor against MRSA. Results of their study concluded that EOs can be applied as a natural anti-MRSA agent on the outer layer of the dressing without disturbing the normal wound healing process. 

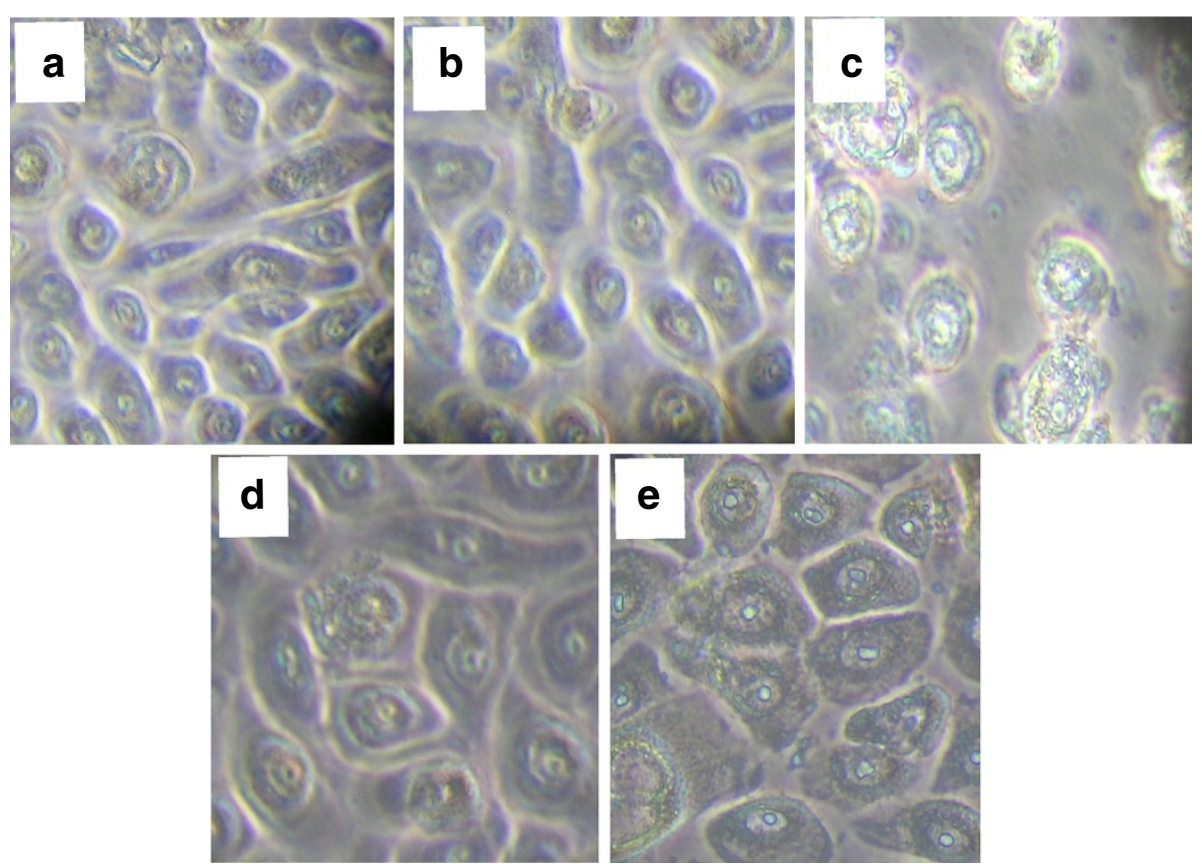

Figure 2 Effect of CPV in Homo sapiens skin keratinocyte (HEK001) ATCC CRL-2404 ${ }^{\text {TM }}$ cell monolayer. (a), normal HEK001 keratinocyte cell monolayer; (b), HEKO01 keratinocyte cell monolayer treated with equal volume of DMSO used in CPV treatment; (c), HEKO01 keratinocyte cell monolayer exhibiting cytotoxic effect caused by SDS $(25 \mu \mathrm{g} / \mathrm{mL}) ;(\mathbf{d})$, HEKO01 keratinocyte cell monolayer treated with $0.1 \%$ CPV; (e), HEK001 keratinocyte cell monolayer treated with $0.2 \%$ CPV. Magnification , x400.

Non-cytotoxic effect of CPV on HEK001 keratinocyte cells Dermal exposure to either synthetic or natural chemical substances can lead to a wide variety of skin reactions. Therefore, it is important to evaluate the new topical therapy agents that can potentially affect the skin cells [51]. Skin is the first-line defense against invading pathogens [52], and is composed of three layers, whereas the outermost epidermis is a squamous epithelium that mainly consists of keratinocytes [53]. Therefore, in this study we used keratinocyte cells as an in vitro model to assess the effect of CPV. Since there are general concerns about the toxicity and adverse effects of the plant derived natural products on the host first we evaluated the toxic effect of CPV on human keratinocyte cell monolayer. In our previous study we have shown that the MIC of CPV for the $S$. aureus strains used in the present study as $0.18 \%$ for the strains $13136 \mathrm{p}^{-} \mathrm{m}^{+}$and $13136 \mathrm{p}^{-} \mathrm{m}^{+} \mathrm{V}_{20}$ and $0.2 \%$ for strains COL, Mu50, and N315 [37]. Therefore, to examine whether CPV has toxic effect on keratinocyte cells, $0.1 \%\left(\frac{1}{2} \mathrm{x}\right.$ MIC) and $0.2 \%$ (1x MIC ) of CPV was added to the HEK001 keratinocyte cell monolayer and subsequently at regular intervals the cell monolayers were examined under phase-contrast microscope for any morphological changes caused by the toxic effect of CPV. Figure $2 \mathrm{a}$ is a representative picture of normal keratinocyte cells and DMSO treated cells did not show any toxic effect and looks similar to normal keratinocyte cells (Figure 2b). Figure 2c represents the cytotoxic effect caused by a known skin irritant SDS on cell monolayer. Compared to controls (Figure 2a-c), CPV $(0.1 \%$ and $0.2 \%)$ treated keratinocyte monolayer cells did not exhibit any toxic response even after $24 \mathrm{~h}$ of incubation (Figure 2d,e). Result of this observation indicated that the concentration $(0.1$ and $0.2 \%)$ of CPV that has previously shown to be bactericidal for MRSA and VISA cells did not produce any adverse effect on human epidermal keratinocyte cells [37]. Host tolerance is one of the issues that must be considered when evaluating natural antibacterial agents [54]. Many currently available antifungal and antibacterial agent possess undesirable toxicity [16,54]. However, interestingly in our in vitro study the CPV treatment on keratinocyte cells did not exhibit any toxic effect mediated cell death in keratinocyte cells. It indicates the potential suitability of CPV for the topical antimicrobial treatment for dermal $S$. aureus infections.

\section{Anti-staphylococcal effect of CPV in S. aureus infected keratinocyte cells}

Enumeration of total number $S$. aureus cells infected in HEK001 keratinocyte monolayer indicated that addition of CPV $(0.1 \%$ or $0.2 \%)$ into the infected cells reduced the adhesion of MRSA strain COL and VISA strain $13136 \mathrm{p}^{-} \mathrm{m}^{+} \mathrm{V}_{20}$ to the keratinocyte cells. Infected HEK001 monolayers treated with fresh K-SFM medium alone or 
Table 2 Effect of CPV treatment on the total number of S. aureus infected with skin keratinocyte (HEK001) cell monolayer

\begin{tabular}{|c|c|c|c|c|c|}
\hline \multirow[t]{3}{*}{ S. aureus Strain } & \multirow{3}{*}{$\begin{array}{c}\text { Initial } \\
\text { Inoculum } \\
{ }^{\mathrm{a}}(\mathrm{Log} \\
\text { CFU/mL) }\end{array}$} & \multirow{3}{*}{$\begin{array}{l}\text { Incubation } \\
\text { Time (h) }\end{array}$} & \multirow{3}{*}{$\begin{array}{c}\text { Control } \\
{ }^{\mathrm{a}}(\mathrm{Log} \\
\text { CFU/mL })\end{array}$} & \multirow{2}{*}{\multicolumn{2}{|c|}{$\begin{array}{l}\text { CPV Treatment } \\
{ }^{\mathrm{a}}(\mathrm{Log} \text { CFU/mL) }\end{array}$}} \\
\hline & & & & & \\
\hline & & & & $0.1 \%$ & $0.2 \%$ \\
\hline \multirow[t]{3}{*}{$\mathrm{COL}$} & $7.48 \pm 0.16$ & 1 & $5.53 \pm 0.45$ & $2.84 \pm 0.20$ & $2.18 \pm 0.42$ \\
\hline & & 2 & $5.79 \pm 0.07$ & $2.06 \pm 0.38$ & $1.60 \pm 0.00$ \\
\hline & & 3 & $6.30 \pm 0.07$ & $1.98 \pm 0.45$ & ND \\
\hline \multirow[t]{3}{*}{$13136 \mathrm{pm}^{-} \mathrm{v}_{20}$} & $7.34 \pm 0.11$ & 1 & $5.04 \pm 0.13$ & $3.47 \pm 0.20$ & $2.62 \pm 0.05$ \\
\hline & & 2 & $5.58 \pm 0.06$ & $2.83 \pm 0.15$ & $1.68 \pm 0.15$ \\
\hline & & 3 & $5.88 \pm 0.07$ & $2.29 \pm 0.62$ & ND \\
\hline
\end{tabular}

${ }^{a}$ Inhibition zones are average values of three independent trials \pm standard deviation of the mean $(S D, n=6)$. ND - Not detectable.

K-SFM medium mixed with equal volume of DMSO used in CPV treatment were used as controls in this experiment. We did not observe any difference between these two controls (data not shown). Compared to the control, CPV treated keratinocyte exhibited gradual decreases in total numbers of attached $S$. aureus cells within $3 \mathrm{~h}$ of treatment. After $3 \mathrm{~h}$ of incubation with $0.2 \% \mathrm{CPV}$ number of viable $\mathrm{COL}$ and $13136 \mathrm{p} \mathrm{m}^{-} \mathrm{V}_{20}$ cells became undetectable (Table 2). There are also several clinical studies $[55,56]$ and case reports $[57,58]$ reporting the successful use of EOs in treating MRSA nasal carriage or MRSA infections. Dryden et al. [55] and Caelli et al. [59] reported that a topical tea tree oil treatment was as effective as standard therapy for reducing MRSA nasal colonization. Sherry et al. demonstrated the successful use of the commercial phytochemical mixture Polytoxinol ${ }^{\mathrm{TM}}$ containing the extracts from Lemongrass, Eucalyptus, Melaleuca, Clove, Thyme as well as B.H.T. (Butylated Hydroxy Toluene), Triclosan (0.3\%) and 95 undematured ethano (69.7\%) to treat an intractable MRSA infection of the tibia in an adult patient [58]. Previous case studies have also demonstrated the topical use of Eucalyptus oil extracted from the Eucalyptus globulus leaf together with bioethanol for MRSA wound infection. This case study has reported that without administering any antibiotic application of $0.5 \mathrm{~g}$ of the oil per day to the wound for three weeks improved wound healing with clearing the MRSA to an undetectable level [60]. Recently, Palaniappan and Holley showed that natural antimicrobials carvacrol, thymol, and cinnamaldehyde were able to substantially decrease the MIC of antibiotics in a diverse group of bacteria containing genetic elements responsible for drug resistance [61]. They have demonstrated the synergistic effect of carvacrol, thymol, and cinnamaldehyde in the reduced MIC's of ampicillin, penicillin and bacitracin against penicillin-resistant $S$. aureus [61]. Thus, we speculate it is possible to use the CPV either single topical agent or synergistically with other antibiotics to control the $S$. aureus skin infections.

\section{Conclusions}

MRSA is common in the U.S. and it accounts for more than half of all soft-tissue and skin infections [2]. Surveillance reports indicate that in the U.S. annual MRSA prevalence continuously increased over the 10-year period from $32.7 \%$ in 1998 to $53.8 \%$ in 2007 and during the 1999-2006 the percentage of $S$. aureus infections resistant to methicillin increased greater than $90 \%$ in outpatients admitted to U.S. hospitals. Also, MRSA-related hospitalization rate per 1,000 discharges doubled in 2007 [62,63]. Despite major advances in wound and burn management in the new millennium, infection still remains an important factor in wound healing [6]. Novel classes are clearly needed for MRSA, because current drug classes exhibit emerging resistance. We have initiated this study as a first step towards the investigation of potential antistaphylococcal effect of CPV and its usage for skin infection. In this study, we have demonstrated the antistaphylococcal effect of CPV in an in vitro dressing model and $S$. aureus infected keratinocyte cell culture study. Overall in the present study our findings suggest that further in vivo studies of CPV are warranted since the CPV showed the inhibition and bactericidal effect on MRSA and VISA in the in vitro models. While, we provide interesting and valuable basic data for CPV we suggest prior to continuing on for further studies to test the clinical safety and efficacy of the CPV to use as topical anti-MRSA agent comparison of the inhibitory effect of CPV with antibiotics currently used to treat MRSA skin infection would provide additional valid information for the future therapeutic applications.

In our earlier study we have reported the bacteriolytic effect and mechanism of action of CPV in antibiotic resistant $S$. aureus [37]. The next step in this CPV series study focuses the comparison of the inhibitory effect of CPV with standard antibiotic disc assay together with a quality control strains to develop a standard evaluation method to test the inhibitory effect of CPV on more $S$. aureus strains and other pathogens. 


\section{Abbreviations}

CPV: Terpeneless cold-pressed valencia orange oil; EO: Essential oil; MRSA: Methicillin-resistant Staphylococcus aureus; VISA: Vancomycin intermediate-resistant Staphylococcus aureus.

\section{Competing interests}

The authors declare that they have no competing interests.

\section{Authors' contributions}

AM designed and performed the experiments, interpreted the results and drafted the manuscript. AM and DB designed and performed the cell culture experiment and data analysis. PGC, SCR, and BJW participated in the design of the study. SCR critically read the manuscript and participated in revision of the manuscript. All authors have read and approved the final manuscript.

\section{Author details}

${ }^{1}$ Center for Food Safety and Department of Food Science, University of Arkansas, Fayetteville, AR 72701, USA. ${ }^{2}$ Current address: Department of Animal and Avian Sciences, University of Maryland, College Park, MD 20742 USA. ${ }^{3}$ Microbiology Group, Department of Biological Sciences, Illinois State University, Normal, IL 61790, USA.

Received: 5 November 2011 Accepted: 8 August 2012 Published: 16 August 2012

\section{References}

1. Otto M: Basis of virulence in community-associated methicillin-resistant Staphylococcus aureus. Annu Rev Microbiol 2010, 64(1):143-162.

2. Chen AE, Goldstein M, Carroll K, Song X, Perl TM, Siberry GK: Evolving epidemiology of pediatric Staphylococcus aureus cutaneous infections in a Baltimore hospital. Pediatr Emerg Care 2006, 22(10):717.

3. Hersh AL, Chambers HF, Maselli JH, Gonzales R: National trends in ambulatory visits and antibiotic prescribing for skin and soft-tissue infections. Arch Intern Med 2008, 168(14):1585-1591.

4. Kish TD, Chang MH, Fung HB: Treatment of skin and soft tissue infections in the elderly: A review. Am J Geri Pharmacother 2010, 8(6):485-513.

5. Koerner R, Johnson AP: Changes in the classification and management of skin and soft tissue infections. J Antimicrob Chemother 2011, 66(2):232-234

6. Edwards-Jones V, Greenwood JE: What's new in burn microbiology?: James Laing Memorial Prize Essay 2000. Burns 2003, 29(1):15-24.

7. Guggenheim M, Zbinden R, Handschin AE, Gohritz A, Altintas MA, Giovanoli $P$ : Changes in bacterial isolates from burn wounds and their antibiograms: A 20-year study (1986-2005). Burns 2009, 35(4):553-560.

8. Edwards-Jones V, Dawson MM, Childs C: A survey into toxic shock syndrome (TSS) in UK burns units. Burns 2000, 26(4):323-333.

9. Novick RP: MEDICINE: Combating Impervious Bugs. Science 2008, 319(5865):910-911.

10. Pirri G, Giuliani A, Nicoletto SF, Pizzuto L, Rinaldi AC: Lipopeptides as anti-infectives: a practical perspective. Centr Eur J Biol 2009, 4(3):258-273

11. Stein RA: Antibiotic resistance: A global, interdisciplinary concern. The Am Biol Teacher 2011, 73(6):314-321.

12. Saxena S, Kumar D: Tailoring biodiversity for the development of new therapeutics. Nat Prod Rad 2002, 1:18-25.

13. Singh SB, Barrett JF: Empirical antibacterial drug discovery-Foundation in natural products. Biochem Pharmacol 2006, 71(7):1006-1015.

14. Butler MS, Buss AD: Natural products - The future scaffolds for novel antibiotics? Biochem Pharmacol 2006, 71(7):919-929.

15. Patwardhan B, Mashelkar RA: Traditional medicine-inspired approaches to drug discovery: can Ayurveda show the way forward? Drug Discov Today 2009, 14(15-16):804-811.

16. Saleem M, Nazir M, Ali MS, Hussain H, Lee YS, Riaz N, Jabbar A: Antimicrobial natural products: an update on future antibiotic drug candidates. Nat Prod Rep 2010, 27(2):238-254.

17. McChesney JD, Venkataraman SK, Henri JT: Plant natural products: Back to the future or into extinction? Phytochemistry 2007, 68(14):2015-2022.

18. Saravolatz LD, Markowitz N, Arking L, Pohlod D, Fisher E: Methicillin-resistant Staphylococcus aureus. Ann Intern Med 1982, 96(1):11-16.

19. Burt S: Essential oils: their antibacterial properties and potential applications in foods: a review. Inter J Food Microbiol 2004, 94:223-253.
20. Halcón L, Milkus K: Staphylococcus aureus and wounds: A review of tea tree oil as a promising antimicrobial. Am J Infect Con 2004, 32(7):402-408.

21. Fisher K, Phillips C: Potential antimicrobial uses of essential oils in food: is citrus the answer? Trends Food Sci Technol 2008, 19(3):156-164

22. Hammer KA, Carson CF, Riley TV, Nielsen JB: A review of the toxicity of Melaleuca alternifolia (tea tree) oil. Food Chem Toxicol 2006, 44(5):616-625.

23. Cox S, Gustafson J, Mann C, Markham J, Liew Y, Hartland R, Bell H, Warmington J, Wyllie S: Tea tree oil causes $\mathrm{K}^{+}$leakage and inhibits respiration in Escherichia coli. Lett Appl Microbiol 1998, 26:355-358.

24. Elsom GKF, Hide D: Susceptibility of methicillin-resistant Staphylococcus aureus to tea tree oil and mupirocin. J Antimicrob Chemother 1999, 43(3):427-428.

25. Hammer KA, Carson CF, Riley TV: Antimicrobial activity of essential oils and other plant extracts. J Appl Microbiol 1999, 86(6):985-990.

26. May J, Chan CH, King A, Williams L, French GL: Time-kill studies of tea tree oils on clinical isolates. J Antimicrob Chemother 2000, 45(5):639-643.

27. Takarada K, Kimizuka R, Takahashi N, Honma K, Okuda K, Kato T: A comparison of the antibacterial efficacies of essential oils against oral pathogens. Oral Microbiol Immunol 2002, 19:61-4.

28. Brady A, Loughlin R, Gilpin D, Kearney $P$, Tunney M: In vitro activity of tea-tree oil against clinical skin isolates of meticillin-resistant and -sensitive Staphylococcus aureus and coagulase-negative staphylococci growing planktonically and as biofilms. J Med Microbiol 2006, 55(10):1375-1380.

29. Prabuseenivasan S, Jayakumar M, Ignacimuthu S: In vitro antibacterial activity of some plant essential oils. BMC Complem Alt Med 2006, 6(1):39.

30. Chao S, Young G, Oberg C, Nakaoka K: Inhibition of methicillin-resistant Staphylococcus aureus (MRSA) by essential oils. Flavour Fragrance J 2008 23(6):444-449

31. Fisher K, Phillips CA: The effect of lemon, orange and bergamot essential oils and their components on the survival of Campylobacter jejuni, Escherichia coli 0157, Listeria monocytogenes, Bacillus cereus and Staphylococcus aureus in vitro and in food systems. J Appl Microbiol 2006 101(6):1232-1240.

32. O'Bryan CA, Crandall PG, Chalova VI, Ricke SC: Orange essential oils antimicrobial activities against Salmonella spp. J Food Sci 2008 73(6):M264-M267.

33. Friedly EC, Crandall PG, Ricke SC, Roman M, O'Bryan C, Chalova VI: In vitro antilisterial effects of citrus oil fractions in combination with organic acids. J Food Sci 2009, 74(2):M67-M72.

34. Shannon EM, Milillo SR, Johnson MG, Ricke SC: Efficacy of cold-pressed terpeneless Valencia oil and its primary components on inhibition of Listeria species by direct contact and exposure to vapors. J Food Sci 2011 76(7):M500-M503.

35. Nannapaneni R, Muthaiyan A, Crandall PG, Johnson MG, O'Bryan CA, Chalova VI, Callaway TR, Carroll JA, Arthington JD, Nisbet DJ: Antimicrobial activity of commercial citrus-based natural extracts against Escherichia coli 0157: H7 isolates and mutant strains. Foodborne Pathog Dis 2008, 5(5):695-699.

36. Nannapaneni R, Chalova VI, Crandall PG, Ricke SC, Johnson MG, O'Bryan CA: Campylobacter and Arcobacter species sensitivity to commercial orange oil fractions. Int J Food Microbiol 2009, 129(1):43-49.

37. Muthaiyan A, Martin EM, Natesan S, Crandall PG, Wilkinson BJ, Ricke SC: Antimicrobial effect and mode of action of terpeneless cold-pressed Valencia orange essential oil on methicillin-resistant Staphylococcus aureus. J Appl Microbiol 2012, 112(5):1020-33.

38. Horsburgh MJ, Aish JL, White IJ, Shaw L, Lithgow JK, Foster SJ: sigmaB modulates virulence determinant expression and stress resistance: characterization of a functional rsbU strain derived from Staphylococcus aureus 8325-4. J Bacteriol 2002, 184(19):5457-67.

39. Sabath LD, Wallace SJ, Byers K, Toftegaard I: Resistance of Staphylococcus aureus to penicillins and cephalosporins: reversal of intrinsic resistance with some chelating agents. Ann N Y Acad Sci 1974, 236:435-43.

40. Brown DF, Reynolds PE: Intrinsic resistance to beta-lactam antibiotics in Staphylococcus aureus. FEBS Lett 1980, 122(2):275-278.

41. Kuroda M, Ohta T, Uchiyama I, Baba T, Yuzawa H, Kobayashi I, Cui L, Oguchi A, Aoki K, Nagai Y: Whole genome sequencing of meticillin-resistant Staphylococcus aureus. Lancet 2001, 357(9264):1225-1240.

42. Pfeltz RF, Singh VK, Schmidt JL, Batten MA, Baranyk CS, Nadakavukaren MJ, Jayaswal RK, Wilkinson BJ: Characterization of passage-selected vancomycin-resistant Staphylococcus aureus strains of diverse parental backgrounds. Antimicrob Agents Chemother 2000, 44(2):294-303. 
43. Braddock RJ: Handbook of citrus by-products and processing technology. New York: Willey; 1999.

44. Goñi P, López P, Sánchez C, Gómez-Lus R, Becerril R, Nerín C: Antimicrobial activity in the vapour phase of a combination of cinnamon and clove essential oils. Food Chem 2009, 116(4):982-989.

45. Edwards-Jones V, Buck R, Shawcross SG, Dawson MM, Dunn K: The effect of essential oils on methicillin-resistant Staphylococcus aureus using a dressing model. Burns 2004, 30(8):772-777.

46. Chung NM, Marshall CM, Leyden JJ, Lavker RM, Jensen PJ, Marsh BCR: Sodium dodecyl sulfate induces plasminogen activator inhibitor type 2 expression in epidermal keratinocytes in vivo and in vitro. J Invest Dermatol 2001, 117(3):647-653

47. Harvey HA, Jennings MP, Campbell CA, Williams R, Apicella MA: Receptor-mediated endocytosis of Neisseria gonorrhoeae into primary human urethral epithelial cells: the role of the asialoglycoprotein receptor. Mol Microbiol 2001, 42(3):659-672.

48. Dorman HJD, Deans SG: Antimicrobial agents from plants: antibacterial activity of plant volatile oils. J App/ Microbiol 2000, 88(2):308-316.

49. Gaunt LF, Higgins SC, Hughes JF: Interaction of air ions and bactericidal vapours to control micro-organisms. J Appl Microbiol 2005, 99(6):1324-1329.

50. Lopez P, Sanchez C, Batlle R, Nerin C: Solid-and vapor-phase antimicrobial activities of six essential oils: susceptibility of selected foodborne bacterial and fungal strains. J Agric Food Chem 2005, 53(17):6939-6946.

51. Van de Sandt J, Roguet R, Cohen C, Esdaile D, Ponec M, Corsini E, Barker C, Fusenig N, Liebsch M, Benford D: The use of human keratinocytes and human skin models for predicting skin irritation. The Report and Recommendations of ECVAM Workshop. ATLA 1999, 27:723-744.

52. Gallo RL, Nakatsuji T: Microbial symbiosis with the innate immune defense system of the skin. J Invest Dermatol 2011, 131(October 2011):1974-1980.

53. Welss T, Basketter DA, Schröder KR: In vitro skin irritation: facts and future. State of the art review of mechanisms and models. Toxicol In Vitro 2004, 18(3):231-243

54. Woolf AD: Herbal remedies and children: Do they work? Are they harmful? Pediatrics 2003, 112(1):240-246.

55. Dryden MS, Dailly S, Crouch M: A randomized, controlled trial of tea tree topical preparations versus a standard topical regimen for the clearance of MRSA colonization. J Hosp Infect 2004, 56(4):283-286.

56. Sherry E, Warnke PH: Successful use of an inhalational phytochemical to treat pulmonary tuberculosis: A case report. Phytomedicine 2004 11(2-3):95-97.

57. Caelli M, Porteous J, Carson CF, Heller R, Riley TV: Tea tree oil as an alternative topical decolonization agent for methicillin-resistant Staphylococcus aureus. J Hosp Infect 2000, 46(3):236-237.

58. Sherry E, Boeck H, Warnke P: Percutaneous treatment of chronic MRSA osteomyelitis with a novel plant-derived antiseptic. BMC Surgery 2001, $1(1): 1$

59. Caelli M, Porteous J, Carson CF, Heller R, Riley TV: Tea tree oil as an alternative topical decolonization agent for methicillin-resistant Staphylococcus aureus. Int J Aromather 2001, 11(2):97-99.

60. Sherry E, Boeck H, Warnke PH: Topical application of a new formulation of eucalyptus oil phytochemical clears methicillin-resistant Staphylococcus aureus infection. Am J Infect Control 2001, 29(5):346-346.

61. Palaniappan K, Holley RA: Use of natural antimicrobials to increase antibiotic susceptibility of drug resistant bacteria. Int J Food Microbiol 2010, 140(2-3):164-168.

62. Klein E, Smith DL, Laxminarayan R: Community-associated methicillin-resistant Staphylococcus aureus in outpatients, United States, 1999-2006. Emerg Infect Dis 2009, 15(12):1925-1930

63. Mera RM, Suaya JA, Amrine-Madsen H, Hogea CS, Miller LA, Lu EP, Sahm DF, O'Hara P, Acosta CJ: Increasing role of Staphylococcus aureus and community-acquired methicillin-resistant Staphylococcus aureus infections in the United States: A 10-year trend of replacement and expansion. Microb Drug Resist 2011, 17(2):321-328.

doi:10.1186/1472-6882-12-125

Cite this article as: Muthaiyan et al:: Application of orange essential oil as an antistaphylococcal agent in a dressing model. BMC Complementary and Alternative Medicine 2012 12:125.

\section{Submit your next manuscript to BioMed Central and take full advantage of:}

- Convenient online submission

- Thorough peer review

- No space constraints or color figure charges

- Immediate publication on acceptance

- Inclusion in PubMed, CAS, Scopus and Google Scholar

- Research which is freely available for redistribution 